\title{
Q\&A How are you meeting the new CPD requirements?
}

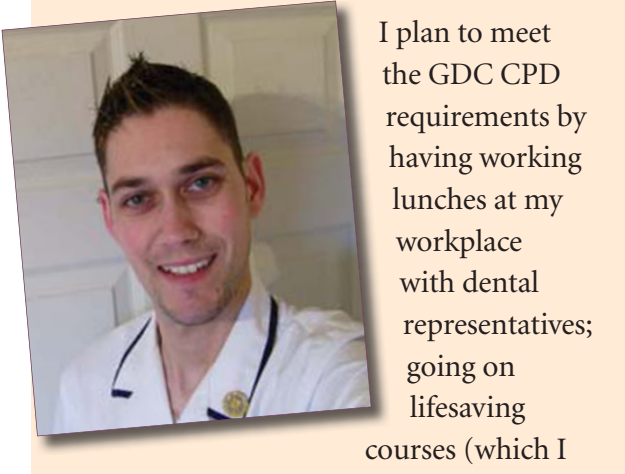

attended in 2008) and also attending training days, courses and trade shows (I will be attending one in November this year). I will also be reading magazines for dental nurses, and other relevant literature available to nursing staff.

\section{Gavin Ward \\ Senior Dental Nurse, Lincoln}

So far I've completed nearly 15 hours of $\mathrm{CPD}$ - a mixture of verifiable and nonverifiable. This has been done through a variety of methods: formal study days, free publications like Team DSR, reading study books and dental magazines. Plus some online study.

I have also attended two really interesting courses via the Scout Association as I am a

Cub Scout Leader - Young People Today and Conflict Resolution.

Young People Today was about the needs and influences of young people at set stages in their lives. Conflict Resolution was not just your usual how to deal with an aggressive person but was from the young person's perspective - why it's important to find out what is causing the conflict and the many imaginative ways to deal with it.

I will shortly be starting the NEBDN Oral Health Education Certificate at King's Dental Nurse Education Centre. They also run Dental Nurse Post Qualifications as well as day seminars on different things which cover many CPD hours; I am due to go on one shortly called Introduction to CPD.

Also I recently found out the London
Deanery are running very cost effective verifiable Core CPD days for dental nurses from as little as $£ 10$, which is something I will be booking to go on.

Last but not least - you can also get general and verifiable CPD from reading Vital - which is highly informative and interesting, and such a great and fun magazine to read!

\section{Ali Parker, Dental Nurse}

Ed's note - I didn't pay Ali to say this!

Snail mail: Vital Editorial, NPG 4-6 Crinan Street, London N1 9XW Next issue's star letter writer will win Colgate goodies worth $£ 100$.

Letters may be edited for space. Opinions expressed do not necessarily reflect those of the editorial team or publishers.

\section{'Ethics and consent can be a minefield'}

The newest thing to hit dental practices in my locality has been the noticeably large influx of patients we treat who originate from other countries. We are becoming a much more multicultural society and as such it can potentially lead to communication barriers, which make gaining valid consent and important medical details complex.

Recently I have been looking into communication barriers and possible solutions as part of our clinical governance. I designed a set of 'quick sheets' which are simple laminated sheets containing basic commonly used dental and medical phrases in a variety of languages that the dentist/patient can use in order to gain valuable information more effectively. It is not ideal by any means, so we as a practice are looking into external services/ resources that are available.

In relation to treating a more diverse population, we have also had to start considering other issues recently when we realised one of our haemostatic aids contains gelatine. Some ethnic minorities as well as vegetarian and vegan patients could possibly refuse to accept such products based on religious or moral beliefs if they knew what they contained. Should we now be routinely informing such patients of this fact?

As professionals we are taught to be reflective practitioners and provide our care based on current best practice guidelines and evidence based research, however, issues such as ethics and consent can be a minefield in modern dentistry and we are faced with dilemmas such as patient autonomy vs. benefit to the patient on a regular basis.

\section{Bernadette Tierney} By email 